\title{
Collision avoidance using a model of the locust LGMD neuron
}

\section{Report}

Author(s):

Blanchard, Mark; Verschure, Paul F.M.J.

Publication date:

2001

Permanent link:

https://doi.org/10.3929/ethz-a-004266422

Rights / license:

In Copyright - Non-Commercial Use Permitted

Originally published in:

INI's posters 


\section{Collision avoidance using a model of the locust LGMD neuron}

Mark Blanchard, Paul F.M.J. Verschure

Laboratory of Neuromorphic Robotics and Synthetic Epistemology (LNRSE)

Institute of Neuroinformatics, University/ETH Zürich, Winterthurerstrasse 190, CH-8057 Zürich

www.ini.unizh.ch
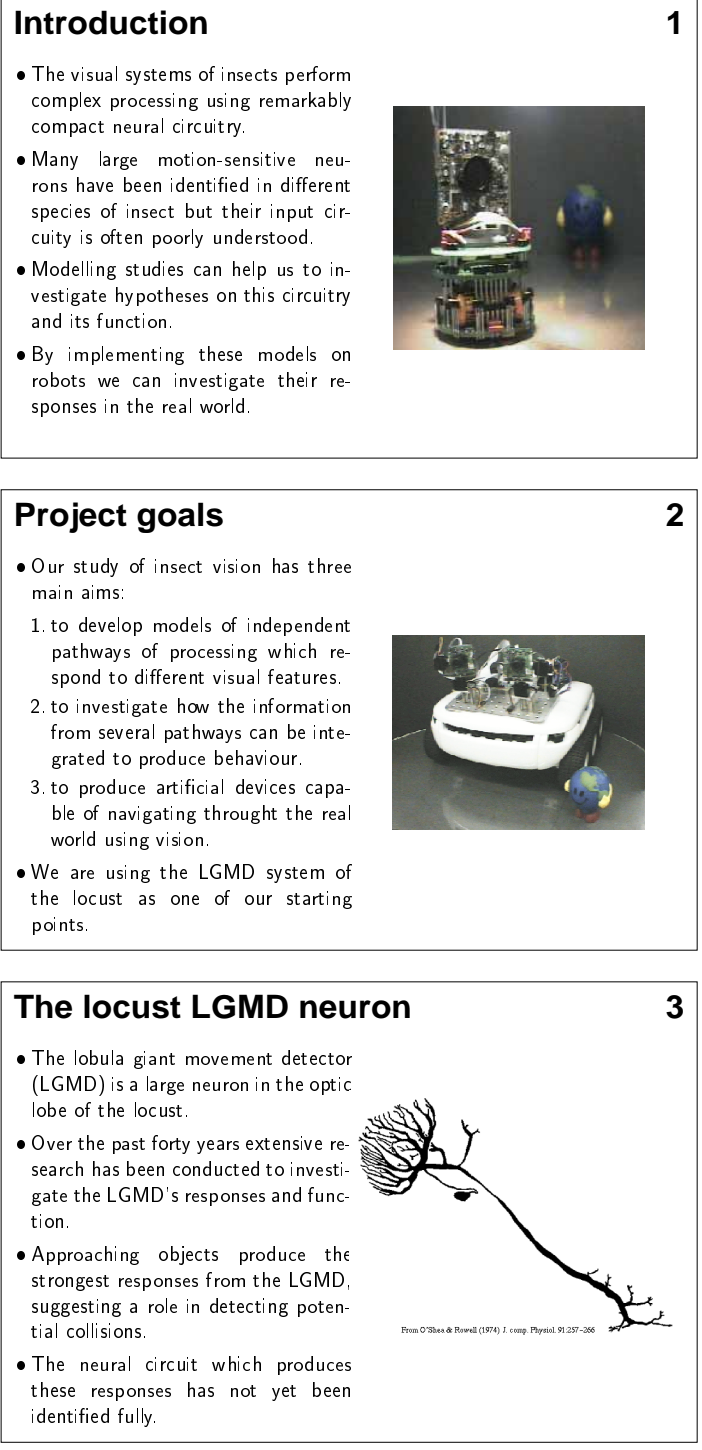
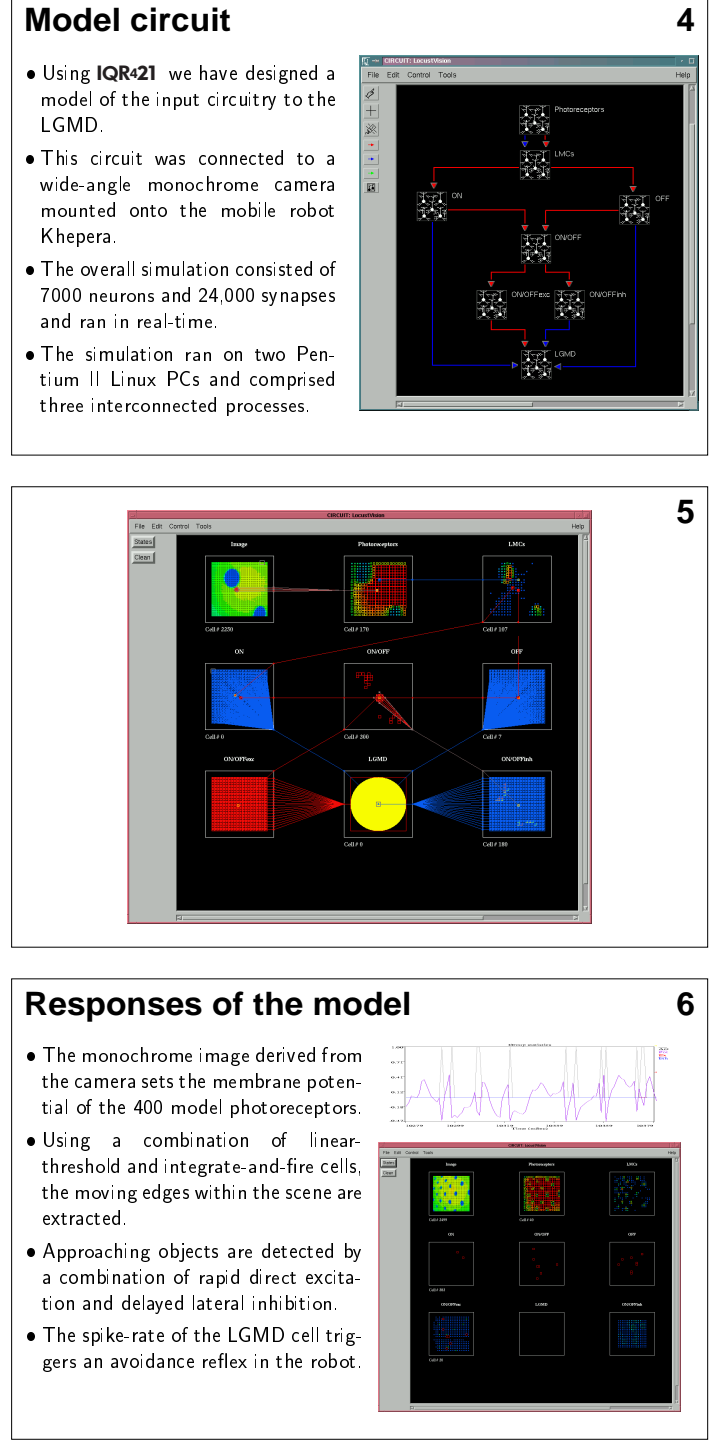
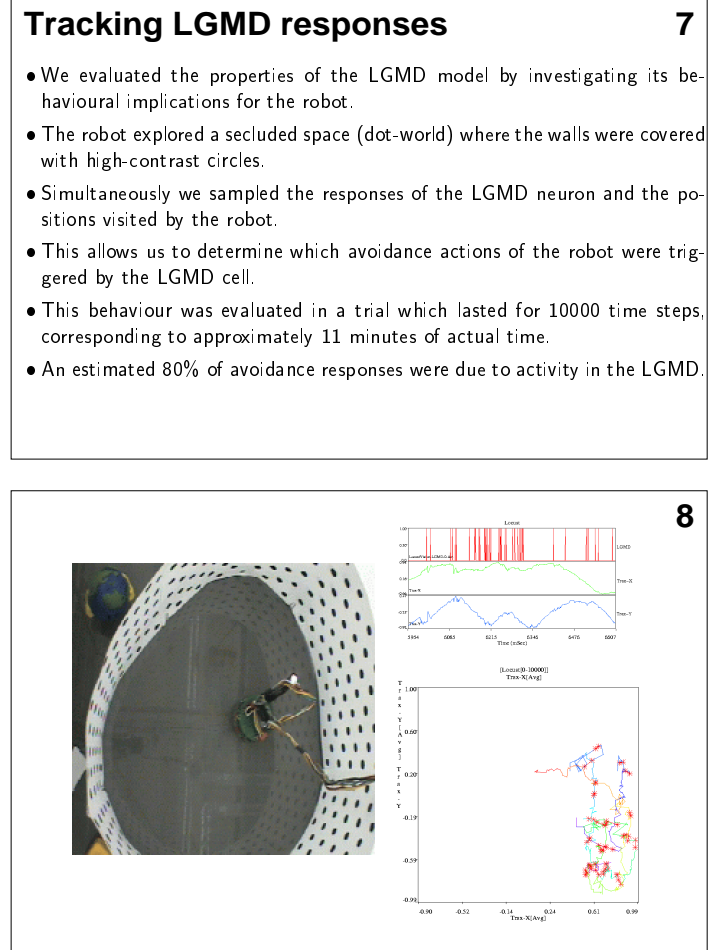

Conclusions

9

- Our preliminary results show that a model which is accurately reflecting basic properties of the LGMD neuron and its afferent circuitry produces robust visually-guided avoidance behaviour on a mobile robot.

- In subsequent work we will investigate more closely the detailed respons properties of this model and its ability to respond in more natural environments.

-We will also extend our study of insect vision to explore other motion

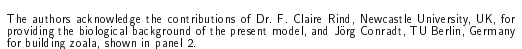

